\title{
Propriedades físicas e químicas do mel de Apis mellifera $\mathrm{L}$.
}

\author{
Physical and chemical properties of Apis mellifera L. hone
}

\section{Fernanda Dias Bartolomeu ABADIO FINCO ${ }^{1 \star}$, Luciana Learte MOURA ${ }^{1}$, Igor Galvão SILVA ${ }^{1}$}

\section{Resumo}

O presente trabalho teve como objetivo verificar as propriedades físicas e químicas do mel da região Sul do Estado do Tocantins a partir de 24 amostras provenientes de 13 associações de apicultores. As análises realizadas foram pH, acidez, índice de refração, umidade, peso específico, cinzas, hidroximetilfurfural (Prova qualitativa), índice de formol, reação de Lund e açúcares redutores. Todas as análises foram realizadas em triplicata, o tratamento estatístico compreendeu média, desvio padrão e os resultados foram submetidos à análise fatorial e análise de agrupamento. As amostras apresentaram índice de reprovação de $50 \%$ aos padrões estabelecidos pela legislação. A grande variação nos resultados entre as amostras podem ser devido a diferentes origens florais dos méis e a sua inadequação à legislação pode ter origem na exposição do produto a condições de temperatura e umidade inadequadas, nas etapas de manejo, processamento ou armazenamento do mel.

Palavras-chave: mel; Apis mellifera; caracterização; análise de agrupamento.

\begin{abstract}
This study aimed at verifying the physical and chemical properties of 24 samples of honey produced by 13 beekeeper associations from Southern Tocantins State, Brazil. The following analyses were performed: $\mathrm{pH}$, titatrable acidity, refractive index, moisture, ash, specific weight, hydroxymetilfurfural (qualitative probe), formol index, Lund reaction, and inverted sugar. All analyses were performed in triplicates, and the statistical analysis comprised mean, standard deviation, factor analysis, and cluster analysis. The samples presented a failure index of $50 \%$ regarding the legislation standards. The considerable variation of results can be due to the different honey floral origins and the failure to meet the standards established by national legislation may be due to the exposition of the honey to inappropriate conditions of temperature and humidity during the honey beekeeping, processing, or storage.
\end{abstract}

Keywords: honey; Apis mellifera; characterization; cluster analysis.

\section{Introdução}

Segundo a legislação brasileira (BRASIL, 2000), mel é

[...] o produto alimentício produzido pelas abelhas melíferas, a partir do néctar das flores ou das secreções procedentes de partes vivas das plantas ou de excreções de insetos sugadores de plantas que ficam sobre partes vivas de plantas, que as abelhas recolhem, transformam, combinam com substâncias específicas próprias, armazenam e deixam madurar nos favos da colmeia[...]

A hipótese de que este produto possua propriedades terapêuticas tem contribuído para que seja utilizado como agente de terapia natural devido às suas ações antibacteriana, antibiótica, anticárie, anti-inflamatória, antimicrobiana, bioestimulante, depurativa, emoliente, energética, imunoestimulante e cicatrizante (MATSUNO, 1997; MOTHERSHAW; JAFFER, 2004; HORIE et al., 2004; BEKERS et al., 2004; WAILI-AL, 2004; AL et al., 2009). A procura por produtos naturais tem gerado uma demanda crescente por produtos apícolas e, ao mesmo tempo, uma maior participação do mel na alimentação humana. Atualmente, o mel tem sido considerado não apenas por suas propriedades terapêuticas, mas também como suplemento alimentar sem a adição de outras substâncias durante a sua elaboração. Este fato se justifica visto que a simples análise do mel demonstra claramente a riqueza nutritiva de sua composição, que inclui micronutrientes como vitaminas, minerais (AZEREDO, L. C.; AZEREDO, M. A. A.; DUTRA, 2003).

A composição física e química e características sensoriais como sabor e cor do mel podem sofrer variações de acordo com a sua origem floral e por tal motivo, para fins de comercialização, o mel pode ser classificado de acordo com sua origem botânica e procedimento de obtenção (CRANE, 1983; BRASIL, 2000).

Nas regiões tropicais, as características físicas e químicas do mel ainda são pouco conhecidas, visto que a flora apícola é bastante diversificada, associada às taxas elevadas de umidade e temperatura. Assim, a caracterização de méis é fundamental para o conhecimento de suas propriedades físicas e químicas

Recebido para publicação em 25/6/2008

Aceito para publicação em 8/7/2009 (003605)

${ }^{1}$ Laboratório de Segurança Alimentar e Nutricional, Universidade Federal do Tocantins - UFT, Av. NS 15, AL C NO 14, Estação Experimental, Campus Universitário de Palmas, CEP 77000-00, Palmas - TO, Brasil, E-mail: fabadio@gmail.com

${ }^{*}$ A quem a correspondência deve ser enviada 
levando-se em consideração os fatores edafoclimáticos e estabelecendo critérios comparativos de análise entre diversas regiões (CRANE, 1983).

$\mathrm{O}$ mel é ainda considerado um produto de baixo risco toxicológico, sendo raro que apresente algum efeito tóxico. Todavia, pode haver plantas que produzem méis tóxicos ou ainda a contaminação por Hidroximetilfurfural quando o produto é exposto a temperaturas superiores a $35^{\circ} \mathrm{C}$ por longos períodos, o que exige cuidados específicos durante a produção e processamento do mel (ZAPPALA et al., 2005; VISQUERT et al., 2004).

A apicultura é considerada uma atividade importante para o setor agropecuário em nível nacional. Os dados sobre a produção brasileira de mel não são precisos, entretanto estima-se que, entre janeiro e julho de 2002, o Brasil exportou 10,615 toneladas de mel e que no futuro o mercado internacional possa absorver 170 mil toneladas/ano de mel oriundo do Brasil (EMPRESA..., 2009). Em adição aos aspectos econômicos, a apicultura brasileira reúne alguns requisitos que também a credencia como uma atividade de elevado potencial de inclusão social, atendendo às características econômicas, sociais e ambientais, ou seja, do desenvolvimento sustentável (MOREIRA, 1996).

No Tocantins, a apicultura se inclui entre as atividades econômicas mais promissoras do estado, especialmente devido às condições ambientais favoráveis, pois, além de possuir um cerrado propício à criação de abelhas como bioma predominante, possui também grandes áreas livres de contaminações de defensivos agrícolas (APICULTURA..., 2007). Em adição, a apicultura possui um importante papel social no estado visto que esta é predominantemente desenvolvida por pequenos produtores rurais reunidos em associações de apicultores. Atualmente, há 1000 produtores reunidos em 28 associações no Tocantins (SEAGRO, 2009).

Atualmente a produção ainda é considerada pequena, quando comparada à outros estados do Brasil se restringindo ao mercado local. Entretanto, diversas iniciativas têm sido realizadas pelos poderes público e privado em prol deste segmento no estado, com o intuito de não apenas estimular a produção de mel, mas garantir qualidade ao produto.

Como produto de origem animal, todo mel comercializado está sujeito aos padrões preconizados pela legislação. Até recentemente há pouca informação disponível na literatura científica que mencione as características físicas e químicas do mel produzido no Estado do Tocantins.

O objetivo deste trabalho foi caracterizar os méis produzidos na região Sul do Estado do Tocantins por meio de análises químicas e físicas.

\section{Material e métodos}

\subsection{Material}

Amostras de mel $(n=24)$ de origens florais diversas foram obtidas, entre os meses de abril e outubro, na safra de 2005, junto a associações de apicultores localizadas nos seguintes municípios da região Sul do Tocantins: Aliança do Tocantins, Gurupi, Araguaçú, Sucupira do Tocantins, Crixás,
Carariense, Apijaú do Tocantins, Cariri, Dueré e Figueirópolis. As amostras foram coletadas em porções de aproximadamente $500 \mathrm{~g} \mathrm{em}$ frasco de polietileno natural, e transportadas em caixas térmicas protegidas de luz, calor e umidade, sendo encaminhadas ao Laboratório de Segurança Alimentar e Nutricional, Universidade Federal do Tocantins - UFT, para realização imediata das análises.

\subsection{Análises físicas e químicas dos méis}

pH, acidez titulável, índice de formol, prova de Lund e açúcares redutores

O valor de $\mathrm{pH}$, acidez titulável, índice de formol, prova de Lund e açúcares redutores foram determinados segundo as Normas Analíticas do Instituto Adolfo Lutz (1985).

\section{Umidade e peso específico}

Determinados por refratometria a $20^{\circ} \mathrm{C}$, sendo utilizado refratômetro (Marca Quimis - modelo Q-109B). Para interpretação dos dados de umidade, foi utilizada a tabela de Chataway (VERÍSSIMO, 1991).

\section{Cinzas}

A quantificação de cinzas foi obtida por incineração de uma quantidade conhecida da amostra, em mufla a $600^{\circ} \mathrm{C}$ até obtenção de peso constante (VERÍSSIMO, 1991).

\section{Hidroximetilfurfural (HMF)}

Esta análise foi realizada pela Reação de Fiehe (prova qualitativa), a qual é um teste colorimétrico que se baseia na adição de éter na amostra, para evaporação da camada etérea e solução clorídrica de resorcina. Apresentando glicose comercial ou mel superaquecido, cujo resultado positivo exibe uma coloração vermelha (IAL, 1985).

\section{Condutividade elétrica}

A condutividade elétrica foi obtida em uma solução a $20 \%$ de matéria seca de mel a $20^{\circ} \mathrm{C}$ (ACQUARONE; BUERA; ELIZALDE, 2007). Para sua determinação, foi utilizado condutivímetro digital (Marca: Instrutherm, modelo CDR870).

\section{Análise estatística}

Todas as análises foram realizadas em triplicata. As análises estatísticas utilizadas compreenderam média e desvio padrão. Posteriormente, os resultados foram submetidos à análise fatorial e análise de agrupamento, as quais têm sido utilizadas em trabalhos com o objetivo de classificação de mel (MARCHINI; MORETI; OTSUK, 2005; SODRÉ, 2007; SANTOS et al., 2008; BARONI et al., 2009). Os resultados das análises físicas e químicas foram submetidos à análise fatorial utilizando-se o método de componentes principais. Após análise da matriz de correlação, as variáveis que apresentaram correlação $>0,7$ foram excluídas para retirar o efeito de multicolinearidade (JOLIFFE, 
1973). O teste de esfericidade de Bartlett e teste KMO (KaiserMeyer-Olkin) de adequação da amostragem também foram aplicados para verificar se a matriz de correlação poderia ser considerada idêntica. Estes testes indicam se a matriz de dados é apropriada para prosseguir com a análise fatorial.

A análise de agrupamento foi realizada utilizando-se o método Ward e a distância euclidiana quadrada e os grupos foram extraídos utilizando-se como critério de definição os gráficos das distâncias de ligação nos sucessivos passos da análise de agrupamento. Após a identificação dos grupos, os resultados das análises físicas e químicas foram submetidos ao teste $t$ de comparação de médias $(\mathrm{p}<0,05)$.

A análise estatística foi realizada no software SPSS versão 16.0 (SPSS, EUA, 2001).

\section{Resultados e discussão}

Os resultados das análises físicas e químicas foram expressos por média e desvio padrão e comparados aos valores sugeridos pela Instrução Normativa ${ }^{\circ} 11$ do Ministério da Agricultura e do Abastecimento conforme Tabela 1 (BRASIL, 2000).

Os valor médio obtido para acidez livre foi de $44,7 \pm 7,7$ Meq.Kg ${ }^{-1}$ (35,0 a 59 Meq.Kg $\left.{ }^{-1}\right)$. Quando comparados aos valores preconizados pela legislação, $33,33 \%$ das amostras se encontraram em desacordo, com valores acima do permitido. Bendini e Souza (2008) encontraram valor médio de 30,21 Meq. $\mathrm{Kg}^{-1} \mathrm{em}$ méis provenientes da florada do cajueiro e atribuíram às características físicas e químicas encontradas nas amostras à especificidade da florada.

A acidez do mel deve-se à variação dos ácidos orgânicos causada pelas diferentes fontes de néctar, pela ação da enzima glicose-oxidase que origina o ácido glucônico, pela ação das bactérias durante a maturação do mel e ainda a quantidade de minerais presentes no mel, podendo ser ainda explicada pela presença de ácidos orgânicos em equilíbrio com suas lactonas correspondentes ou ésteres internos e alguns íons inorgânicos, como fosfato (WHITE JUNIOR, 1989; FINOLA et al., 2007). Desta forma, a acidez do mel é um componente de extrema relevância, pois além de conferir características químicas e sensoriais, contribui para a sua estabilidade frente ao desenvolvimento de microrganismos (CORNEJO, 1988).
Não há indicação de análise de pH como obrigatória para avaliação da qualidade do mel, esta, no entanto, foi realizada como parâmetro complementar para a avaliação da acidez total. Os valores de $\mathrm{pH}$ variaram entre 3,35 e 4,50. Azeredo, L. C., Azeredo, M. A. A e Dutra (2003) encontraram valor médio de $\mathrm{pH}$ de 3,5 em doze amostras de méis de diferentes floradas.

Crane (1983) cita que o valor de $\mathrm{pH}$ pode estar diretamente relacionado com a composição florística nas áreas de coleta, uma vez que o $\mathrm{pH}$ do mel pode ser influenciado pelo $\mathrm{pH}$ do néctar, além das diferenças na composição do solo ou a associação de espécies vegetais para a composição final do mel.

O resultado para umidade apresentou valor médio de $16,2 \%$, variando entre 18,9 a $21 \%$. Entretanto, ao se comparar os valores de umidade com a legislação vigente, observou-se que 33,3\% das amostras ultrapassaram os limites preconizados (BRASIL, 2000). O conteúdo de água no mel é uma das características mais importantes e constitui o segundo componente em quantidade, variando conforme o clima, a origem floral e época de colheita. O teor de umidade é o principal fator determinante de parâmetros como viscosidade, peso específico, cristalização e sabor, além de ser um indicativo importante da tendência à fermentação influenciando principalmente na conservação do produto (SEEMANN; NEIRA, 1988; MORAES; TEIXEIRA, 1998). De acordo com Marchini, Moreti e Otsuk (2005) uma das prováveis razões para valores de umidade acima do permitido, poderia ser a colheita do mel oriundo de favos não operculados ou ainda período e/ou condições de armazenamento inadequados, podendo assim, o mel ter absorvido umidade do ambiente. Desta forma, é importante que as condições de processamento e armazenamento das amostras sejam avaliadas, de forma a identificar a provável causa dos elevados e inadequados valores de umidade encontrados nas amostras analisadas.

Por meio da análise de cinzas é possível determinar algumas irregularidades no mel, como por exemplo, a falta de higiene e a não decantação e/ou filtração no final do processo de retirada do mel pelo apicultor (VILHENA; ALMEIDA-MURADIAN, 1999). Os resultados das amostras estudadas variaram de 0,01 a $0,30 \%$, permanecendo de acordo com a legislação brasileira que estabelece o limite máximo de 0,6\% (BRASIL, 2000). Amostras de mel produzidas no Estado de São Paulo e analisadas por Marchini, Moreti e Otsuk (2005) também apresentaram valores de cinza dentro do limite estabelecido pela legislação.

Tabela 1. Média e Desvio Padrão (DP) para as análises físicas e químicas.

\begin{tabular}{|c|c|c|c|c|c|}
\hline \multirow[t]{2}{*}{ Características } & \multirow{2}{*}{$\begin{array}{l}\text { Preconizado pela } \\
\text { legislação* }\end{array}$} & \multicolumn{3}{|c|}{ Méis analisados $(\mathrm{n}=24)$} & \multirow{2}{*}{$\begin{array}{l}\text { Amostras em desacord } \\
\text { com a legislação* }(\%)\end{array}$} \\
\hline & & Média \pm DP & Mínimo & Máximo & \\
\hline Acidez (MEq. $\left.\mathrm{Kg}^{-1}\right)$ & Máximo 50 & $44,7 \pm 7,7$ & 35,0 & 59,0 & 20,83 \\
\hline Umidade (\%) & Máximo 20 & $18,9 \pm 1,7$ & 16,2 & 21,0 & 33,33 \\
\hline Cinzas (\%) & Máximo 0,60 & $0,14 \pm 0,09$ & 0,01 & 0,30 & - \\
\hline Açúcares redutores (\%) & Mínimo de 65 & $68,94 \pm 3,65$ & 62,70 & 76,20 & 4,16 \\
\hline $\mathrm{pH}$ & - & $3,7 \pm 0,2$ & 3,4 & 4,2 & - \\
\hline Índice de Formol $\left(\mathrm{mL} \cdot \mathrm{Kg}^{-1}\right)$ & - & $7,65 \pm 1,05$ & 6,00 & 10,00 & - \\
\hline Peso específico $\left(20^{\circ} \mathrm{C}\right)$ & - & $1,41 \pm 0,01$ & 1,40 & 1,43 & - \\
\hline Lund $(\mathrm{mL})$ & - & $3,63 \pm 2,22$ & 2,00 & 12,00 & - \\
\hline Condutividade elétrica $\left(\mu \mathrm{S} . \mathrm{cm}^{-1}\right)$ & - & $585 \pm 203$ & 300 & 1040 & - \\
\hline Reação de fiehe (positivo) & - & - & - & - & 25 \\
\hline \multicolumn{5}{|c|}{ Total de amostras apresentando algum parâmetro em desacordo com a legislação (\%) } & 50 \\
\hline
\end{tabular}

${ }^{*}$ (BRASIL, 2000) 
O teor de cinzas também expressa a riqueza do mel em minerais e constitui-se num parâmetro bastante utilizado nas determinações que visam verificar sua qualidade (LASCEVE; GONNET, 1974). O baixo conteúdo de cinzas em algumas amostras pode ser característico de méis florais, e a ampla faixa de valores para cinzas pode indicar ainda não uniformidade nas técnicas de manejo e/ou colheita por parte dos produtores (FINOLA et al., 2007). O teor mineral do mel está diretamente relacionado com o tipo do solo e condições climáticas (MONTENEGRO; FREDES, 2008). Aquarone, Buera e Elizalde (2007), estudando méis argentinos, encontraram resultados semelhantes de cinzas para amostras oriundas de diferentes solos, sugerindo que a origem floral seja a maior responsável pelo conteúdo mineral das amostras. Silva, Queiroz e Figueirêdo (2004), analisando méis do Piauí encontraram diferença significativa entre o conteúdo de cinzas de méis de floradas diferentes.

Adicionalmente, produtos com quantidades de cinzas acima do permitido $(0,6 \%)$ podem indicar também elevados índices de poluição. Desta forma, já seria esperado que as amostras não excedessem os limites preconizados, visto que o Tocantins tem como vantagem grandes áreas livres de contaminação.

Em relação aos açúcares, elevadas concentrações de diferentes tipos de açúcar são responsáveis pelas diversas propriedades físicas e químicas do mel, tais como: viscosidade, densidade, higroscopicidade, capacidade de granulação (cristalização). A norma brasileira estabelece um mínimo de $65 \%$ de açúcares redutores, e todas as médias apresentadas pelas diferentes amostras enquadraram-se nestas especificações, com exceção de uma amostra que apresentou resultado mínimo de $62,7 \%$, representando 4,16\% das amostras analisadas (BRASIL, 2000). Em estudo realizado por Barth et al. (2005) em amostras de mel do Estado de São Paulo, duas amostras não alcançaram o valor mínimo de $65 \%$ para açúcares redutores, e Komatsu (1996), ao analisarem o conteúdo de açúcares em méis de flores silvestres, de eucalipto, e de laranjeira no Estado de São Paulo, encontraram apenas uma amostra de mel silvestre não fora do limite da norma vigente (BRASIL, 2000).

Os resultados encontrados para índice de formol variaram entre os valores de 6,0 a $10 \mathrm{~mL} \cdot \mathrm{kg}^{-1}$ com valor médio de $7,65 \pm 1,05$. O índice de formol representa predominantemente, os compostos aminados, permitindo assim avaliar o conteúdo em peptídeos, proteína e aminoácidos. Esta análise é importante indicador de adulteração, pois, quando muito baixo, pode indicar a presença de produtos artificiais, enquanto que excessivamente alto demonstra que as abelhas podem ter sido alimentadas com hidrolisado de proteínas (SIMAL; HUIDOBRO, 1984).

O teste de Lund apresentou resultados variando de 2,0 a 12,0 mL de depósito. A reação de Lund identifica substâncias albuminoides, componentes normais no mel e que são precipitados pelo ácido tânico adicionado. Segundo as Normas Analíticas do Instituto Adolfo Lutz (1985), um depósito acima de $3 \mathrm{~mL}$ indica que o mel é de má qualidade. Os resultados provenientes de oito mostras $(33,33 \%)$ encontraram-se acima deste valor de referência, indicando comprometimento na qualidade destas amostras. Esta análise sugere perdas ou adição de substâncias proteicas durante o processamento do produto (BERA; MURADIAN, 2007).
Em relação à condutividade elétrica, as amostras variaram de 340 a $1040 \mu \mathrm{S} . \mathrm{cm}^{-1}$. A condutividade elétrica está relacionada com o conteúdo de cinzas, $\mathrm{pH}$, acidez, sais minerais, além da proteína e outras substâncias presentes no mel, e este parâmetro é conhecido como prova de origem botânica para méis (STEFANINI, 1984; CRANE, 1990; BOGDANOV et al., 1999; SERRANO et al., 2004). Horn et al. (1996) apresentaram uma variação de 100 a $2103 \mu$ S.cm ${ }^{-1}$ em 57 amostras de méis de diferentes regiões do Brasil.

Não há padrões definidos para condutividade elétrica na legislação atual (BRASIL, 2000), entretanto, este parâmetro é sugerido por Bogdanov et al. (1999) para compor os padrões internacionais para mel com limite máximo de $800 \mu \mathrm{S} . \mathrm{cm}^{-1}$, visto que a condutividade elétrica é um bom critério para definir a origem botânica do mel. Serrano et al. (2004), analisando diversos parâmetros por meio da análise discriminante em méis da região de Andaluzia, Espanha, verificaram que a condutividade elétrica e a atividade de água alcançaram os maiores resultados com poder de classificação nos méis, podendo classificar até $96,6 \%$ dos casos. Aquarone, Buera e Elizalde (2007) também encontraram resultados de que a condutividade elétrica pode ser considerada um importante marcador geográfico para as amostras de méis argentinos.

Os resultados da análise qualitativa para o $\mathrm{HMF}$ demonstraram que $25 \%$ das amostras apresentaram resposta positiva à reação de Fiehe. Sodré et al. (2007) encontraram 20\% de amostras com valores acima do permitido pela legislação vigente no Estado do Ceará e menciona que o alto valor de $\mathrm{HMF}$ no mel é um indicador de superaquecimento, armazenamento inadequado ou adulteração com açúcar invertido.

O HMF é formado pela decomposição da frutose em presença de ácidos e o seu conteúdo pode aumentar com a elevação da temperatura, armazenamento inadequado, adição de açúcar invertido, acidez, $\mathrm{pH}$, umidade e minerais contidos no mel (WHITE JUNIOR, 1989; SEEMANN; NEIRA, 1988; SALINAS; ESOINOSA-MANSILLA; BERZAS-VEVADO, 1991). Segundo Veríssimo (1991), o HMF é considerado um indicador de qualidade no mel, e, quando o produto possui valores elevados desta substância, tal fato pode indicar uma queda no valor nutritivo pela destruição de algumas vitaminas e enzimas termolábeis. White Junior, (1992) sugere que méis de países subtropicais, devido às altas temperaturas, podem ter naturalmente um alto conteúdo de HMF sem que o mel tenha sido superaquecido ou adulterado, o que ratifica a necessidade de controle da qualidade em todo o processo de produção do mel no Tocantins.

Comparando-se os parâmetros analisados com a os Padrões de Identidade e Qualidade normatizados pelo Ministério da Agricultura, constata-se que 50\% das amostras apresentavam alguma não conformidade com os limites estabelecidos pela legislação. Araújo, Silva e Sousa (2006) encontraram 90\% das dez amostras de mel coletadas em pontos de comercialização, tais como supermercados, farmácias, lojas de produtos apícolas e lojas de produtos naturais na cidade de Crato - CE.

Sodré et al. (2007), analisando vinte amostras coletadas diretamente dos produtores no Ceará, constataram que $65 \%$ se enquadravam dentro das exigências da legislação. Silva, Queiroz e Figueirêdo (2004) não encontraram qualquer irregularidade 
em méis de diferentes floradas e municípios do Estado do Piauí. Entretanto, Welke et al. (2008), não encontrou irregularidades quando analisou 18 amostras de mel comercializadas por produtores em feiras livres na região Noroeste do Rio Grande do Sul.

Com o objetivo de classificar as amostras, os resultados das análises físicas e químicas foram submetidos à análise fatorial. Após análise da matriz de correlação, a variável peso específico foi excluída por apresentar multicolinearidade (correlação $>0,7$ ) (JOLIFFE, 1973). Este resultado já era esperado, visto que esta variável é calculada a partir dos resultados de índice de refração, utilizando-se a Tabela de Chataway. Desta forma, manteve-se a variável umidade para a análise de fatores, eliminando-se a questão de multicolinearidade da análise. O teste de KMO apresentou baixo índice $(0,424)$ e o teste de esfericidade de Bartlett não foi significativo ( $\mathrm{p}<0,05)$, demonstrando que a matriz de dados não é apropriada para a análise fatorial. Como caráter ilustrativo, os resultados das estimativas da variância para os fatores encontram-se na Tabela 2.

A análise fatorial extraiu cinco componentes principais explicando $86,19 \%$ da variância, sendo que os dois primeiros explicam apenas $44,71 \%$ da variância, confirmando os resultados dos testes de KMO e Bartellet. Resultados semelhantes foram encontrados por Marchini, Moreti e Otsuk (2005). Diante da impossibilidade de se utilizar o método de redução de variáveis denominado análise fatorial, optou-se por aplicar o método de classificação conhecido como análise de agrupamento ou análise de cluster (Figura 1).

Considerando as análises físicas e químicas realizadas, dois grupos foram extraídos pela análise de agrupamento, os quais tiveram as médias de seus resultados comparadas (Tabela 3). Os grupos apresentaram diferença significativa entre as variáveis acidez e índice de formol.

Tabela 2. Total da variância explicada.

\begin{tabular}{ccc}
\hline Componentes & \multicolumn{2}{c}{ Amostras de mel } \\
\cline { 2 - 3 } & Autovalores & \% Variância acumulada \\
\hline 1 & 1,938 & 24,222 \\
2 & 1,640 & 44,719 \\
3 & 1,547 & 64,052 \\
4 & 0,940 & 75,807 \\
5 & 0,831 & 86,199 \\
\hline
\end{tabular}

O grupo 1 teve acidez média de 37,63 $\pm 2,41 \mathrm{MEq} \cdot \mathrm{Kg}^{-1} \mathrm{e}$ o grupo 2, 50,76 \pm 4,72 MEq. $\mathrm{Kg}^{-1}$. Marchini, Moreti e Otsuk (2005) também encontraram grande variação para acidez em méis silvestre e de eucalipto produzidos no Estado de São Paulo com valores médios de 30,10 $\pm 1,29$ e 33,8 \pm 2,22 MEq. $\mathrm{Kg}^{-1}$, respectivamente. Resultados semelhantes também foram encontrados por outros autores (ARAÚJO; SILVA; SOUSA, 2006; SODRÉ et al., 2007). O índice de formol apresentou grande variação $\left(6,0\right.$ a $\left.10,0 \mathrm{~mL} \cdot \mathrm{Kg}^{-1}\right)$ entre as amostras e diferença significativa $(\mathrm{p}<0,05)$ entre as médias dos grupos extraídos pela análise de agrupamento.

Mendonça et al. (2008), analisando méis em fragmento de Cerrado, também encontraram grande variação para este parâmetro (6,0 a 16,7 mL) e consideraram este resultado como característico de méis de Cerrado. A região sul do estado possui o Cerrado como bioma principal, entretanto, este possui diferentes

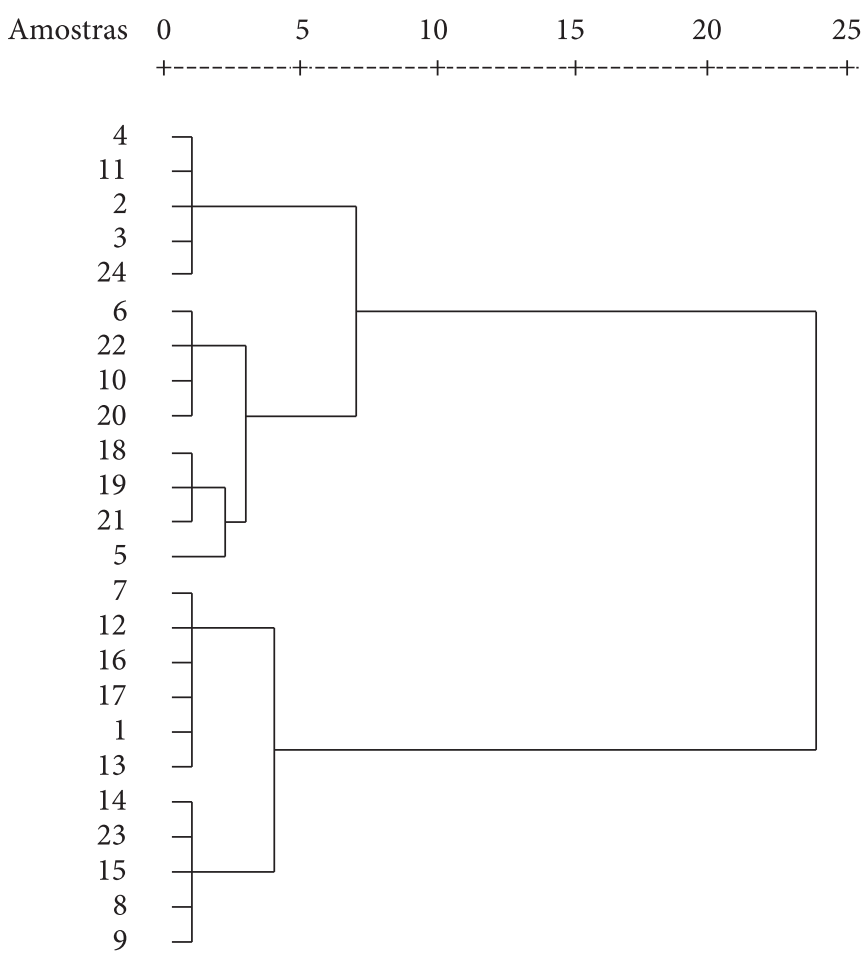

Figura 1. Dendrograma das amostras classificadas pela análise de agrupamento.

Tabela 3. Comparação entre os grupos extraídos na análise de cluster.

\begin{tabular}{lccc}
\hline \multicolumn{1}{c}{ Análise } & Grupo 1 $(\mathrm{n}=11)$ & Grupo 2 (n=12) & p-valor \\
\hline $\mathrm{pH}$ & $3,6 \pm 0,17$ & $3,76 \pm 0,26$ & 0,09 \\
Acidez $\left(\mathrm{MEq.Kg}{ }^{-1}\right)$ & $37,63 \pm 2,41$ & $50,76 \pm 4,72$ & $0,00^{*}$ \\
Umidade (\%) & $18,93 \pm 1,59$ & $18,95 \pm 1,84$ & 0,98 \\
Cinzas (\%) & $0,11 \pm 0,073$ & $0,17 \pm 0,10$ & 0,17 \\
Índice de formol (mL.Kg $\left.{ }^{-1}\right)$ & $7,19 \pm 0,85$ & $8,03 \pm 1,06$ & $0,04^{*}$ \\
Lund $(\mathrm{mL})$ & $3,00 \pm 0,89$ & $4,15 \pm 2,82$ & 0,18 \\
Condutividade elétrica $\left(\mu S . \mathrm{cm}^{-1}\right)$ & $5,4091 \times 10^{-4} \pm 1,56 \times 10^{-4}$ & $6,23 \times 10^{-4} \pm 2,35 \times 10^{-4}$ & 0,33 \\
Açúcares redutores $(\%)$ & $69,0273 \pm 4,06$ & $68,86 \pm 3,42$ & 0,91 \\
\hline
\end{tabular}

${ }^{\star}$ Diferenca significativa entre as médias dos grupos pelo teste $t$. 
ecossistemas (cerrado, cerradão, campestre, mata ciliar), o que pode influenciar a grande variação entre as características físicas e químicas dos méis (MENDONÇA et al., 2008).

\section{Conclusões}

As amostras analisadas apresentaram um índice de reprovação de 50\% quando comparadas aos parâmetros recomendados pela legislação. Diante deste resultado, sugerese que os produtores tenham uma maior preocupação com o controle de qualidade em todas as etapas de produção do mel desde as técnicas de manejo, extração e processamento, modificando eventuais falhas de forma a atender aos requisitos necessários para comercialização e consumo de mel. A acidez variou significativamente entre os grupos, apesar do estudo não ter realizado análise de pólen, os resultados sugerem que a origem floral seja o principal fator para tal variação.

\section{Agradecimentos}

Às associações de apicultores da região Sul do Estado do Tocantins, ao SEBRAE - TO, nas pessoas do Sr. José Carlos Bessa e Paulo Henrique Tschoeke, pelo apoio na etapa de coleta de amostras e interface com as associações. À Prof. Dra. Nedja Fernandes pelo incentivo e amizade na fase inicial deste trabalho. Ao Conselho Nacional de Desenvolvimento Científico e Tecnológico - CNPq pela bolsa de Iniciação Científica.

\section{Referências bibliográficas}

ACQUARONE, C.; BUERA, P.; ELIZALDE, B. Pattern of pH and electrical conductivity upon honey dilution as a complementary tool for discriminating geographical origin of honeys. Food Chemistry, v. 101, p. 695-703, 2007.

AL, L. M. et al. Physico-chemical and bioactive properties of different floral origin honeys from Romania. Food Chemistry, v. 112, p. 863-867, 2009.

Apicultura Integrada e Sustentável - APIS. Disponível em: http://www. apis.sebrae.com.br>. Acesso em: 15 set. 2007.

ARAÚJO, D. R.; SILVA, R. H. D.; SOUSA, J. S. Avaliação da qualidade físico-química do mel comercializado na cidade do Crato-CE. Revista de Biologia e Ciências da Terra, v. 6, n. 1, p. 51-55, 2006.

AZEREDO, L. C.; AZEREDO, M. A. A.; DUTRA, V. M. L. Protein contents and physicochemical properties in honey samples of Apis mellifera of different floral origins. Food Chemistry, n. 80, p. 249-254, 2003.

BARONI, M. V. et al. Composition of honey from Córdoba (Argentina): Assessment of North/South provenance by chemometrics. Food Chemistry, v. 114, n. 2, p. 727-733, 2009.

BARTH, M. O. et al. Determinação de parâmetros físico-químicos e da origem botânica de méis indicados monoflorais do sudeste do Brasil. Ciência e Tecnologia de Alimentos, v. 25, n. 2, p. 229-233, 2005.

BEKERS, M. et al. New prebiotics for functional food. ActaAlimentaria, v. 33, n. 1, p. 31-37, 2004.

BENDINI, J. N.; SOUZA, D. C. Physicochemical characterization of the bee honey originating in cashew flowering. Ciência Rural, v. 38, n. 2, p. 565-567, 2008.
BERA, A.; MURADIAN, L. B. A. Propriedades físico-químicas de amostras comerciais de mel com própolis do estado de São Paulo. Ciência e Tecnologia de Alimentos, v. 27, n. 1, p. 49-52, 2007.

BOGDANOV, S. et al. Honey quality and international regulatory standards: review by the international honey commission. Bee World, v. 80, n. 2, p. 61-69, 1999.

BRASIL. Ministério da Agricultura, Pecuária e Abastecimento. Instrução Normativa 11, de 20 de outubro de 2000. Regulamento Técnico de identidade e qualidade do mel. Disponível em: $<$ http:// www.agricultura.gov.br/das/dipoa/anexo intrnorm11.htm>. Acesso em: jan. 2005.

CORNEJO, L. G. Tecnologia de miel. In: SEEMANN, P.; NEIRA, M. (Ed). Tecnologia de la produccion apicola. Valdivia: Universidad Austral de Chile, Facultad de Ciencias Agrarias, 1988. p. 145-71.

CRANE, E. Bees and beekeeping-science, practice and world resources. London: Neinemann Newnes, 1990.

CRANE, E. O livro do mel. São Paulo: Noel, 1983.

EMPRESA BRASILEIRA DE PESQUISA AGROPECUÁRIA EMBRAPA. Produção de Mel. Importância Econômica. Disponível em: <http://sistemasdeproducao.cnptia.embrapa.br/FontesHTML/ Mel/SPMel/importancia.htm>. Acesso em: 22 abr. 2009.

FINOLA, M. S. et al. Microbiological and chemical characterization of honeys from central Argentina. Food Chemistry, n. 100, p. 1649-1653, 2007.

HORIE, M. etal. Determination of streptomycin and dihydrostreptomycin in honey by liquid chromatography-electrospray mass spectrometry. Journal of Liquid Chromatography \& Related Technologies, v. 27, n. 5 , p. 863-874, 2004.

HORN, H. et al. Méis brasileiros: resultados de análises físico-químicas e palinológicas. In: CONGRESSO BRASILEIRO DE APICULTURA, 11., Teresina, 1996. Anais... Teresina: FBA, 1996. p. 403-429.

INSTITUTO ADOLFO LUTZ - IAL. Métodos químicos e físicos para análise de Alimentos. 3 ed. São Paulo, 1985.

JOLIFFE, L. T. Discarding variables in a principal component analysis. I Real Date. Applied Statistics, v. 21, n. 1, p. 21-31, 1973

KOMATSU, S. S. Caracterização físico-química de méis de Apis mellifera L. 1758 (Hymenoptera: Apidae) de diferentes municípios do Estado de São Paulo. 90 f. Tese (Doutorado)-Escola Superior de Agricultura "Luiz de Queiroz", Universidade de São Paulo, Piracicaba, 1996.

LASCEVE, G.; GONNET, M. Analyse por radioactivation du contenu mineral d'un miel. Possibilité de preciser son origine. Apidologie, v. 5, n. 3, p. 201-223, 1974.

MARCHINI, L. C.; MORETI, A. C. C. C.; OTSUK, I. P. Análise de agrupamento, com base na composição físico-química, de amostras de méis produzidos por Apis mellifera L. no Estado de São Paulo. Ciência e Tecnologia de Alimentos, v. 25, n. 1, p. 8-17, 2005.

MATSUNO, T. O efeito terapêutico da própolis. [S.I.]: [s.n.], 1997. v. 1.

MENDONÇA, K. et al. Caracterização físico-química de amostras de méis produzidas por Apis mellifera L. em fragmento de cerrado no município de Itirapina, São Paulo. Ciência Rural, v. 38, n. 6, p. 1748-1753, 2008.

MONTENEGRO, G.; FREDES, C. Relación entre el origen floral y el perfil de elementos minerals en mieles chilenas. Gayana Botanica, v. 65 , n. 1, p. 123-126, 2008.

MORAES, R. M.; TEIXEIRA, E. W. Análises de mel (manual técnico). Pindamonhangaba: SAA/AMA, 1998. 
MOREIRA, A. dos S. Apicultura. 2. ed. Campinas: CATI, 1996.

MOTHERSHAW, A. S.; JAFFER, T. Antimicrobial activity of foods with different physico-chemical characteristics. International Journal of Food Properties, v. 7, n. 3, p. 629-638, 2004.

SALINAS, F.; ESOINOSA-MANSILLA, A.; BERZAS-VEVADO, J. J. Flow-injection determination of HMF in honey by Winkler method. Fresenius Journal of Analytical Chemistry, v. 340, n. 4, p. 250-252, 1991.

SANTOS, J. S. et al. Honey classification from semi-arid, atlantic and transitional forest zones in Bahia, Brazil. Journal of Brazilian Chemical Society, v. 19, n. 3, p. 502-508, 2008.

SEAGRO. Tocantins avança com qualidade na produção do mel. Disponível em: <http://secom.to.gov.br/noticia.php?id=21606>. Acesso em: 22 abr. 2009

SEEMANN, P.; NEIRA, M. Tecnología de la producción apícola. Valdivia: Universidad Austral de Chile/ Facultad de Ciencias Agrarias Empaste, 1988.

SERRANO, S. et al. Chemical and physical parameters of Andalusian honey classification of Citrus and Eucalyptus honeys by discriminant analysis. Food Chemistry, v. 87, p. 619-625, 2004.

SILVA, C. L.; QUEIROZ, A. J. M.; FIGUEIRÊDO, R. M. F. Caracterização físico-química de mési produzidos no Estado do Piauí para diferentes floradas. Revista Brasileira de Engenharia Agrícola e Ambiental, v. 8, n. 2/3, p. 260-265, 2004.

SIMAL, J.; HUIDOBRO, J. Parámetros de calidad de la miel. III. Acidez ( $\mathrm{pH}$ libre, lactónica \& total) e índice de formol. Offarm, v. 3, n. 9, p. 532, 1984.
SODRÉ, G. S. et al. Caracterização físico-química de amostras de méis de Apis mellifera L. (Hymenoptera: Apidae) do Estado do Ceará. Ciência Rural, v. 37, n. 4, 2007.

STEFANINI, R. Variability and analysis of Italian honeys. Apiacta, v. 19, n. 4, p. 109-114, 1984.

VERÍSSIMO, M. T. L. Saiba o que é HMF. A apicultura no Brasil, v. 4, n. 24, p. 31, 1991.

VILHENA, F.; ALMEIDA-MURADIAN, L. B. Análises físico-químicas de méis de São Paulo. Mensagem Doce, v. 53, p. 17-19, 1999.

VISQUERT, M. et al. Changes in the quality parameters of honey caused by thermal processes. Alimentacion-Equipos-y-Tecnologia, v. 23, n. 188, p. 87-92, 2004.

WAILI-AL, N. S. Natural honey lowers plasma glucose, C-reactive protein, homocysteine, and blood lipids in health, diabetic, and hypelipidemic subjects: comparison with dextrose and sucrose. Journal of Medicinal Food, v. 7, n. 1, p. 100-107, 2004.

WELKE, J. E. et al. Caracterização físico-química de méis de Apis mellifera L. da região noroeste do estado do Rio Grande do Sul. Ciência Rural, v. 38, n. 6, p. 1737-1741, 2008.

WHITE JUNIOR, J. W. La miel. In: DADANT, H. La colmena y la abeja mellifera. Montevideo: Hemisfério Sul, 1989. cap.1, p. 21-35.

WHITE JUNIOR, J. W. Quality evaluation of honey: role of HMF and diastase assays. Part II. American Bee Journal, v. 132, n. 12, p. 792-794, 1992.

ZAPPALA, M. et al. Methods for the determination of HMF in honey: a comparison. Food Control, v. 16, n. 3, p. 273-277, 2005. 